enough of the element. As a matter of fact many commercially available solutions and especially those of amino-acids are slightly contaminated with zinc and other elements, but the quantities present are far below actual needs. Some of the newer solutions for parenteral feeding do contain trace elements in adequate amounts, but nevertheless we still frequently have to add further $100-500 \mu \mathrm{g} / \mathrm{day}$ (1-5 $\mathrm{ml}$ of a solution containing $0.1 \mathrm{mg} \mathrm{Zn} / \mathrm{ml}$ as $\mathrm{ZnCl}_{2}$ ), mostly in surgical patients, to achieve positive nitrogen balance, normal wound healing, and growth.

Calculations of the actual amounts of other trace elements in human plasma lead to the same conclusions as to the rationale of its use as a source of trace elements for patients under parenteral nutrition. It is therefore mandatory actually to calculate even microgram amounts and stimulate the pharmaceutical industry to supply adequate solutions for general use.

D H SHMERLING

University Department of
Paediatrics,
Children's Hospital,
Zürich, Switzerland

' Fox, H A, and Krasma, I H, Pediatrics, 1973, 52, 14.
' Halsted, J A, and Smith, J C, Lancet, $1970,1,322$.
'Ricour, C, and Nihoul-Fekete, C, Archives Francaises
de Pediatrie, 1970, $30,469$.
'James, B E, and MacMahon, R A, Medical Fournal of
Australia, 1970, 2, 1161.

\section{Cracking urinary bladder stones}

SIR,-Your interesting leading article (9 July, p 79) suggests that electronic stone disintegration is a safe method of dealing with vesical calculi, though not without significant disadvantages. In my view the method is also accompanied by distinct hazards.

Each underwater spark produces not only the shockwave which you mention but also a bubble of vapour, which expands and contracts extremely rapidly in oscillatory fashion in the subsequent five or so milliseconds. ${ }^{1}$ The maximum size of this bubble depends among other things on the electrical energy used, but in one instrument $^{2}$ (not the one you mention) an energy of 18 joules produces a bubble approximately $3 \mathrm{~cm}$ in diameter. Each time the oscillating bubble reaches a minimum volume it emits a pressure pulse and the first one or two pulses are comparable in destructive force to the preceding shockwave. The process has many similarities, except in scale, to the underwater detonation of high explosive.

Although the oscillating bubble, through its pressure pulses, adds significantly to stone destruction it is not widely appreciated that it also represents the major source of hazard from the technique, not from the pressure pulses (which, like the shock wave, pass relatively harmlessly through the bladder wall) but from the associated violent mass movement of water. Whereas a large stone shields the bladder wall from the vapour bubble and the fluid it rapidly displaces, a smaller fragment may be ejected into or even through the bladder wall if inappropriate power settings and techniques are used. These risks are not merely theoretical as damage to the bladder wall and frank perforation have been reported. ${ }^{3-5}$

The phenomena described make it clear why attempts to use existing disintegrators in the confined space of the ureter have resulted in damage $e^{4}$ and why their recent suggested use in the renal pelvis is inappropriate.

It may nevertheless prove possible to meet the need, to which you direct attention, for instruments to tackle ureteric stones. Modifications to electrode design can produce focusing, enabling power (and hazards from the bubble) to be reduced without loss of effectiveness. It may also prove possible to produce a totally enclosed fluid-filled electrode, thus confining the bubble but permitting passage of the shock wave, but the engineering problems are considerable. Finally, further developments of the device described by Schuy and Schmidt-Kloiber ${ }^{6}$ in which the mechanical energy of external underwater electrical discharges is conveyed to the target calculus by a reciprocating flexible rod may also provide a solution.

Haddington, East Lothian

Michael J TIDD

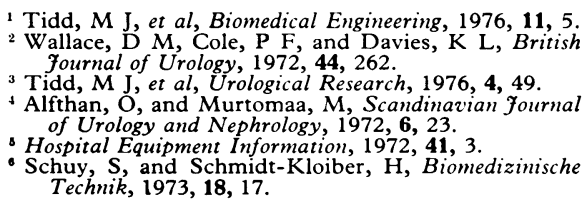

Tuberculous peritonitis with cirrhosis of the liver

SIR,-In your excellent leading article on abdominal tuberculosis in Britain (18 June, p 1557) it is suggested, among other things, that "ascitic fluid with lymphocytosis and high protein concentration should . . . increase the suspicion of tuberculosis." However, in tuberculous peritonitis complicating cirrhosis of the liver the protein concentration of the ascitic fluid may be low. ${ }^{1}$ Tuberculous peritonitis in cirrhotics "is still encountered and is often unsuspected."' We should like to draw attention to such a diagnostic possibility, reporting a case of tuberculous peritonitis complicating cirrhosis in which the protein concentration in the ascitic fluid was low.

A 34-year-old woman was admitted to our department because of ascites under pressure, anorexia, abdominal and right hypochondrial pain, severe weakness, and pyrexia up to $38^{\circ} \mathrm{C}$. The history had started two years previously with progressively deteriorating flatulent dyspepsia and weakness. Four months before admission pyrexia, abdominal pain, and ascites were added. On examination we found stigmata of liver disease, mild jaundice, ascites under pressure, and oedema of the ankles and legs. After we had aspirated about 1.51 of ascitic fluid a large hard spleen with a sharp edge (about $10 \mathrm{~cm}$ below the left costal margin) and many small intra-abdominal lumps were felt. There was no hepatomegaly and no lymph-node enlargement. The blood count and film were normal and the erythrocyte sedimentation rate was $90 \mathrm{~mm}$ in the first hour. The serum albumin concentration was $30 \mathrm{~g} / 1$ and that of globulins $57 \mathrm{~g} / 1$. There was mild elevation of the serum alkaline phosphatase and aspartate and alanine transaminase (SGOT and SGPT) activities. The plasma bilirubin ranged from 32.5 to $107.7 \mu \mathrm{mol} / 1$ (1.9 to $6.3 \mathrm{mg} / 100 \mathrm{ml}$ ) and was mainly conjugated Tests for hepatitis B antigen were positive, for $\alpha$-fetoprotein negative, and smooth-muscle antigen positive. The ascitic fluid was examined twice. The protein content was about $10 \mathrm{~g} / 1$ and the Rivalta reaction negative; there were many leucocytes mainly lymphocytes. Tubercle bacilli were presen in both the specimens. The chest $x$-ray was normal and a tuberculin skin test $(1: 100000)$ was negative. A liver scan was compatible with cirrhosis.

The patient was treated with a conventional triple antituberculosis treatment. After some days the pyrexia declined and finally disappeared and progressively the appetite improved, the $a b$ dominal pain subsided, and the intra-abdominal lumps almost disappeared. The patient was discharged from hospital but unfortunately died about three months later in hepatic coma.

Although the ascitic fluid in tuberculous peritonitis usually contains more than $25 \mathrm{~g}$ of protein/l and in cirrhosis less than $25 \mathrm{~g} / \mathrm{l}$, if the two diseases coexist values greater or less than $30 \mathrm{~g} / 1$ have been reported. ${ }^{1}$ The presence of pyrexia and abdominal pain in a cirrhotic raises the possibility of another disease. Hence the diagnosis of tuberculous peritonitis must be kept in mind when a cirrhotic patient presents with pyrexia and abdominal pain even if the ascitic fluid is a transudate. Thorough examination of the ascitic fluid for tubercle bacilli, including culture and inoculation, is mandatory.

A J ARCHIMANDritis G Rigatos

$S$ BEGIETI

N KaLliakMANIS

S K BARTSOKAS

Department of Pathological

Psychology,

National University of Athen

Greece

Burack, W R, and Hollister, R M, American fournal of $960,28,510$.

Sth edn. Oxford, Blackwell Scientific, 1975. System,
5iseases of the Liver and Biliary

\section{Vitamin $B_{12}$ for vegans}

SIR,-We read your expert's reply (11 June, p 1525) and Mr Alan Long's letter (16 July, $p$ 192) on vegan sources of vitamin $B_{12}$ with interest.

Beliefs that the comfrey plant (Symphytum officinale) is a natural source of vitamin $B_{12}$ persist and are repeated in the current catalogue of at least one firm of horticultural seedsmen and another specialist supplier of herbal products. We therefore extracted $12.5 \mathrm{~g}$ of freshly picked comfrey leaves by boiling in $500 \mathrm{ml}$ acetate buffer (pH 5.0) containing $0.01 \%$ sodium cyanide in preparation for assay. ${ }^{1}$ No vitamin $B_{12}$ was detected in the extract using the Euglena gracilis var bacillaris $z$-strain assay ${ }^{2}$; this implies a vitamin $B_{12}$ concentration of less than $10 \mathrm{ng} / 1$ of extract. Thus $1 \mathrm{~kg}(2 \cdot 2 \mathrm{lb})$ of fresh comfrey leaves could at most have contained $400 \mathrm{ng}(0.4 \mathrm{~kg})$ of vitamin $\mathrm{B}_{12}$.

We therefore conclude that comfrey leaves are not relevant as a source of vitamin $B_{12}$ in mixed, vegetarian, or vegan diets.

\section{RichaRd W PAYNe}

BRIAN F SAVAGE

Department of Pathology,

Worcester Royal Infirmary,

Worcester

${ }^{1}$ Gray, L F, and Daniel, L J, fournal of Nutrition, 1959, 67, 623.
Hutner, S H, Bach, M K, and Ross, G I M, fournal of Protozoology, 1956, 3, 101 .
Putner,

\section{Schistosomal myelopathy}

SIR,-The report of a case of schistosomal myelopathy by $\mathrm{Dr} \mathrm{J}$ Cohen and others (14 May, p 1258) is of great interest, but their conclusion that the cord damage is immunological is open to doubt. The presence of specific antibodies, whether in the serum or the CSF, indicates only that there is an immune reaction and not that pathological changes are due to it. In fact a study of previously reported cases of this condition would indicate that direct involvement of the cord 